Prof. Bell points out the danger which consequently exists of the formation of a distinct deaf-mute variety of mankind.

All this is clearly brought out in Prof. Bell's memoir; but Mr. Packard goes so far as to state that Mr. Bell's statistics appear to "alınost demoristrate the fact of the transmission of characters acquired during the life-time of the individual," and also says that "deaf-mutes already appear to breed true to their incipient strain or variety, whether congenitally deaf or rendered so by disease during the life-time of either or both parents." (The italics are ours). We are thus left in no doubt as to Mr. Packard's interpretation of Mr. Bell's researches; but an attempt on our own part to find in Mr. Bell's pages the particular statistics or remarks which may be regarded as all but demonstrating the inheritance of acquired characters has, remarkably enough, been completely unsuccessful. $\mathrm{Mr}$ Bell's conclusions lend no support to such a view. So far as they bear upon the present subject, they are briefly as follows: (I) That the great factor in determining the production of deaf-muteness in offspring is the existence of a hereditary taint in the direction of deaf-muteness in one or both branches of the family. (2) That this hereditary taint is not the less potent in its effects if it fails to manifest itself in the actual parents of the deafmute. (3) That "non-congenital deafness, if sporadic, is little likely to be inherited."

It would thus appear, both from Chilton's presentation of the facts, and from the failure of Packard's appeal to analogy, that-often as the contrary opinion has been urged-the peculiarities of cavernicolous animals do not lend any particular degree of support to the Lamarckian principles of evolution.

W. G.

\section{PROPOSED BALLOON VOYAGE TO THE POLE.}

$\mathrm{D}$

URING the last century many expeditions to the North Pole have been undertaken, but with no result so far as reaching it is concerned. Baron Nordenskiöld, the great Arctic explorer, has made four expeditions to Spitzbergen, and two to Nova Zemlia and Greenland, besides having taken part in the celebrated voyage of the Vega. In all explorations both he and others have found the icebergs the chief obstacle; and it may be said that Arctic explorers are now almost all unanimously convinced that the Pole can never be reached in steamer or sledge. Attempts on foot have likewise failed, for the distance of about ten miles has never been exceeded, owing to the great difficulties and dangers.

Notwithstanding these facts, Dr. Nansen, the celebrated Norwegian explorer, attempted yet another way, and instead of cutting a path through the ice, he has allowed himself to be carried polewards by a northerly current. This took place a year and eight months ago, and he has not been heard of since.

Quite recently, at the Royal Academy of Science Stockholm, an even more perilous project was proposed by M. Andrée, a Swedish engineer. M. Andrée proposes making the expedition in a balloon. The project is not a new one, but it has never been seriously discussed by Arctic explorers. M. Andrée, however, has had much experience in polar regions, having spent the winter of $1882-83$ in the far north, and also taken part in the Swedish Meteorological Expedition, which lasted a year. $\mathrm{He}$ has also proved himself to be a dauntless aeronaut, his most interesting voyage being one from Gothenburg to the Isle of Gothland, in which he had to cross part of the Baltic. Everything in connection with this proposed expedition has been minutely studied and discussed; and infinite pains have been taken to solve all difficulties.

The balloon would require a double outer covering, and a volume of 6500 cubic yards. The ascensional NO. I 340 , VOL. 52$]$ power thus obtained would be sufficiently great to carry three persons, furnished with provisions for four months, besides allowing for the car being fitted up with necessary instruments for observation, life-buoys, and Berton's collapsible boats. The car could be suspended in such a way as to allow of instant detachment in case of a descent into the sea. The entire weight of the balloon must not exceed about three tons. In the instance of Henri Giffard's captive balloon, exhibited in I878, and which weighed about six tons, it only required newly inflating after a year's use. According to Graham's observations, a balloon measuring $8 \frac{3}{4}$ yards in diameter can be made sufficiently air-tight so as to suffer, per month, merely a loss of $13^{\frac{1}{2}}$ lbs. of its ascensional force. M. Andrée, however, hopes to produce an absolutely impermeable covering.

The balloon, being protected from the wind by a wooden enclosure, would be inflated as far north as possible, by means of hydrogen compressed in cylinders. This once accomplished, it would begin to ascend. To a certain extent it might be steered by means of a sail and several guide-ropes, which, dragging on the earth, form as it were a brake. The ropes, however, would have to be of special composition, in order to produce the same effect in water. The hindrance thus caused to the flight of the balloon, together with the pressure of the wind, would allow the use of a sail. The flight then might reach an angle of $40^{\circ}$ away from the wind direction. This steering apparatus, invented by M. Andrée, has often been used by him in his aerial voyages.

Besides the guide-ropes, heavy lines, on which would be placed numbered metal plates, would be attached to the car; these would serve as ballast. In case of a lowering of temperature, and a consequent descent of the balloon, it could be lightened by throwing off these plates, which, if found, would, to a certain extent, show the course taken by the explorers.

Spitzbergen has been chosen as the starting-point, for this island is almost always clear of ice by the middle of June. The departure would take place in July, on a clear day, with a southerly wind. At Spitzbergen the average rate of wind per second is $10 \frac{1}{2}$ yards ; the guideropes would cause a hindrance of about $2 \frac{3}{4}$ yards per second, therefore the average rate of balloon would be nearly 8 yards per second, which is about 16 miles an hour. At this rate the Pole should be reached in 43 hours.

The summer is in all respects the most suitable time for an aeronautic voyage in Spitzbergen. The lowest temperature observed at Cape Thordsen in July, I 883 was $+0^{c} \cdot 8 \mathrm{C}$., and the highest $+\mathrm{II}^{\mathrm{c}} \cdot 6 \mathrm{C}$. The movements of the balloon would therefore be very regular. Besides this, there are practically no storms, and the fall of snow in June and July is both slight and rare.

M. Andrée's project has been highly approved of by the most experienced Arctic explorers. Baron Nordenskiöld has declared himself in favour of it, and $M$. Eikholm, chief of the Swedish Meteorological Expedition to Spitzbergen in $1882-83$, states that the conditions of the Arctic regions are most favourable for this voyage. He thinks, moreover, that in the future the balloon will be the principal means of exploring that part of the world.

For many of the above details, we are indebted to an article in the Revue Scientifique, by M. Charles Rabot.

\section{W.}

\section{THOMAS HENRY HUXLEY.}

WE regret to announce that, after an illness extending back to last March, and relieved only by two or three brief periods of improving health, Prof. Huxley passed peacefully into the silence of death on Saturday afternoon. 